\title{
Detection of drug-induced apoptosis and necrosis in human cervical carcinoma cells using ${ }^{1} \mathrm{H}$ NMR spectroscopy
}

\author{
T Bezabeh ${ }^{\star, 1}$, MRA Mowat ${ }^{2}$, L Jarolim² ${ }^{2}$ AH Greenberg ${ }^{2}$ and \\ ICP Smith ${ }^{1}$ \\ ${ }^{1}$ Institute for Biodiagnostics, National Research Council, Winnipeg, Manitoba, \\ R3B 1 Y 6 Canada \\ 2 Manitoba Institute of Cell Biology, University of Manitoba, CancerCare \\ Manitoba, Winnipeg, Manitoba, R3E OV9 Canada \\ * Corresponding author: T Bezabeh, Institute for Biodiagnostics, National \\ Research Council, 435 Ellice Ave., Winnipeg, Manitoba, R3B 1Y6 Canada, Tel: \\ (204) 983-0994; Fax: (204) 984-7036; E-mail: Tedros.Bezabeh@nrc.ca
}

Received 3.7.00; revised 30.8.00; accepted 24.10.00

Edited by BA Osborne

\begin{abstract}
Apoptosis and necrosis need to be differentiated in order to distinguish drug-induced cell death from spontaneous cell death due to hypoxia. The ability to differentiate between these two modes of cell death, especially at an early stage in the process, could have a significant impact on accessing the outcome of anticancer drug therapy in the clinic. Nuclear magnetic resonance spectroscopy was used to distinguish apoptosis from necrosis in human cervical carcinoma (HeLa) cells. Apoptosis was induced by treatment with the topoisomerase II inhibitor etoposide, whereas necrosis was induced by the use of ethacrynic acid or cytochalasin $\mathrm{B}$. We found that the intensity of the methylene resonance increases significantly as early as $6 \mathrm{~h}$ after the onset of apoptosis, but that no such changes occur during necrosis. The spectral intensity ratio of the methylene to methyl resonances also shows a high correlation with the percentage of apoptotic cells in the sample $\left(r^{2}=0.965, P<0.003\right)$. Cell Death and Differentiation (2001) 8, 219-224.
\end{abstract}

Keywords: nuclear magnetic resonance spectroscopy; apoptosis; necrosis; HeLa cells; human cervical carcinoma

Abbreviations: Cyt B, cytochalasin B; DMSO, dimethyl sulfoxide; NMR, nuclear magnetic resonance; PBS, phosphate-buffered saline

\section{Introduction}

When cells are exposed to cytotoxic agents, there are various patterns of cell death that they may undergo. ${ }^{1}$ The two major types of cell death are apoptosis and necrosis. Apoptosis or programmed cell death is characterized by cell shrinkage, chromatin condensation and blebbing of the plasma membrane. ${ }^{1-4}$ Accompanying apoptosis is activation of cell death effector proteases (caspases) that attack cytoplasmic and nuclear substrates, ${ }^{5}$ cleavage of DNA into nucleosomesized and larger fragments by caspase-activated endonucleases, ${ }^{6-9}$ and the alteration of plasma membrane phospholipid organization with phosphatidyl serine externalization. ${ }^{10}$ These processes are considered as morphological markers for this type of cell death. The apoptotic cell is rapidly phagocytosed and digested by macrophages or adjacent cells. $^{2,11}$ Apoptosis is activated within several hours of treatment by a wide variety of signals including DNA damage, growth factor deprivation, death receptor signaling, radiation and many cancer chemotherapeutic drugs. ${ }^{12}$ Necrosis, on the other hand, results from an overwhelming physical cellular injury and is generally characterized by cellular and mitochondrial swelling, scattered chromatin condensation, and loss of plasma membrane integrity. ${ }^{2,13}$ Necrosis is usually followed by an inflammatory response to the released cellular contents, often resulting in further tissue damage.

Tumors with a high incidence of necrosis rather than apoptosis show aggressive behavior and generally have a poor prognosis. ${ }^{14}$ Other studies have also shown a relationship between the suppression of apoptotic cell death and subsequent tumor progression in murine models. ${ }^{15,16}$ Thus, the ability to distinguish between these two modes of cell death, especially at very early time points post-treatment, may provide useful information on the success of treatment and the prediction of long-term outcomes in patients with various forms of cancer.

In this study, we have used etoposide (VP-16) to induce apoptosis in human cervical carcinoma (HeLa) cells. Etoposide, an epipodophyllotoxin derivative, induces apoptosis by inhibiting topoisomerase II and generating double strand breaks in DNA. ${ }^{17}$ It is used clinically to treat small cell lung carcinoma with a great deal of success, and lymphoma and acute leukemias with a modest degree of success. ${ }^{17}$ Necrosis was induced by the use of ethacrynic acid or cytochalasin B (Cyt B). Ethacrynic acid, a glutathione-conjugate-forming diuretic, causes necrotic cell death by inhibiting a number of distinct ion-transporting activities. $^{18}$ Early changes by ethacrynic acid include changes in volume regulation, mitochondrial structure and function, and decrease in ATP levels. Late changes include loss of membrane permeability and control of $\mathrm{Ca}^{2+}$ ion levels. Cytochalasin $B$ induces necrosis by inhibiting cytokinesis via the depolymerization of actin microfilaments. ${ }^{19}$ In addition to forcing the cells to die through the necrotic pathway, it also inhibits the formation of apoptotic bodies. $^{20}$

We have carried out proton nuclear magnetic resonance (NMR) spectroscopic studies on control and drug treated human cervical carcinoma (HeLa) cells to monitor the action of the cytotoxic drugs. NMR spectroscopy is a useful technique for detecting compounds of low molecular weight 
and high molecular mobility. Thus, NMR analysis of cells undergoing apoptotic and necrotic cell death may reveal novel metabolic and biochemical changes specifically associated with these processes. Moreover, the changes in the fluidity of the plasma membrane, and thus the mobility of the protons therein, can be studied by monitoring the changes in the intensity of the lipid resonances in the spectrum.

Both ${ }^{31} \mathrm{P}$ and ${ }^{13} \mathrm{C}$ NMR spectroscopy have been used to study apoptotic cell death. ${ }^{21,22}$ These studies have revealed changes in the phospholipid profile during apoptosis. However, it is ${ }^{1} \mathrm{H}$ NMR spectroscopy that has received more attention recently. Blankenberg et al. ${ }^{23}$ have used this technique to detect apoptosis in cells exposed to chemotherapeutic drugs. However, a quantitative correlation between apoptosis and spectral features was only performed for doxorubicin-treated Jurkat T-cells. ${ }^{24}$ Doxorubicin is an anthracycline antibiotic that inhibits DNA function by intercalation. In this study, we have used a different cell line (HeLa cells) and a different drug, etoposide, which has a different mode of action from doxorubicin. This would help to establish the fact that the spectral changes that correlate with apoptotic cell death are true reflections of the actual process and independent of the cells employed, the drug used or the mechanism by which apoptosis is executed, making the technique more robust and widely applicable.

\section{Results}

Figure 1 shows images of apoptotic, necrotic, as well as control HeLa cells after acridine orange/ethidium bromide staining. The yellow arrows in Figure 1c of the etoposide treated cells show late apoptotic cells (dead=orange) with condensation and chromatin clumping. The white arrows show early apoptotic live cells (green) with chromatin superaggregation i.e. highly condensed chromatin. These changes are typical of apoptotic cells and are very different from the cells shown in Figure 1b after treatment with ethacrynic acid. The ethacrynic acid treated cells which are all dead after treatment (orange) show no clumping or chromatin condensation, typical of necrotic cell death.

The cells were harvested at 6,12 , and $24 \mathrm{~h}$ after treatment with the etoposide and the percentage of apoptotic cells was determined at each time point as shown in Figure 2. As can be seen in this figure, about $15 \%$ of the cells became apoptotic as early as $6 \mathrm{~h}$ posttreatment and more than $65 \%$ of the cells became apoptotic at $24 \mathrm{~h}$ after treatment. The ${ }^{1} \mathrm{H}$ NMR spectra shown in Figure 3 demonstrate the effect of etoposide on HeLa cells during apoptotic cell death. An increase in the intensity of the resonance at 1.3 p.p.m. is seen as early as $6 \mathrm{~h}$ after treatment corresponding to approximately $15 \%$ of the cells being apoptotic. The increase in the methylene resonance becomes even more marked at later time points. The $\mathrm{CH}_{3}$ protons of lactate, and the $-\mathrm{CH}_{2}$ protons of the mobile lipid both contribute to the resonance at 1.3 p.p.m. The change in the intensity of the choline $\left[\mathrm{N}\left(\mathrm{CH}_{3}\right)_{3}\right]$ metabolites (3.2 p.p.m.), however, is more gradual and no appreciable decrease is observed until about $12 \mathrm{~h}$ after
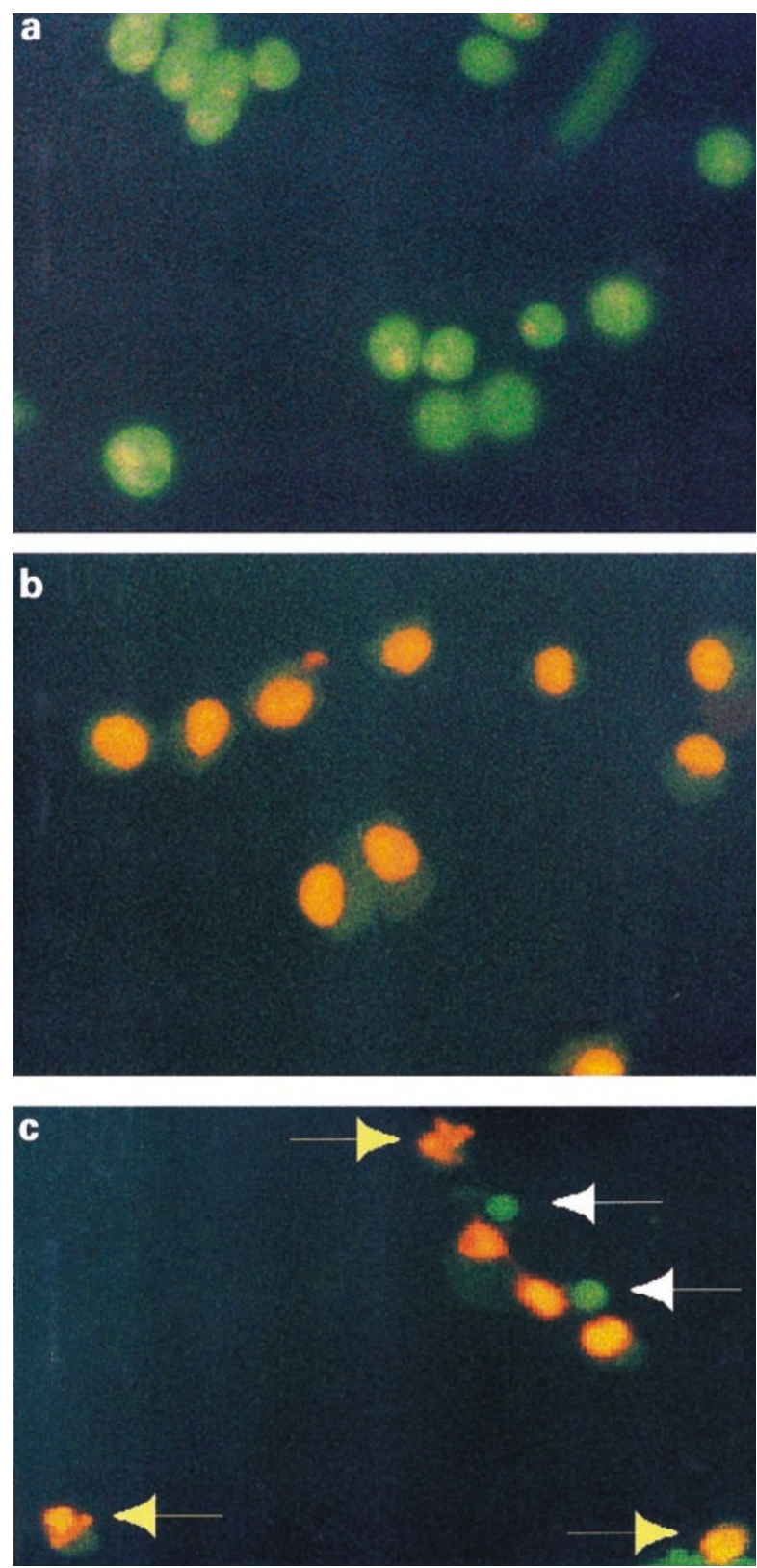

Figure 1 Images of drug treated HeLa cells after acridine orange/ethidium bromide staining (a) controls after $24 \mathrm{~h}$, (b) cells treated with ethacrynic acid for $1.5 \mathrm{~h}$, and (c) cells treated with etoposide for $24 \mathrm{~h}$. The yellow arrows in (c) show late apoptotic cells (dead=orange) with condensation and chromatin clumping and the white arrows show early apoptotic nuclei (live) with chromatin super-aggregation i.e. highly condensed chromatin

treatment. The overall intensity change for the 3.2 p.p.m. resonance, over the $24 \mathrm{~h}$ post-treatment period, is also not as marked as that for the 1.3 p.p.m.

The intensity of the methyl $\left(\mathrm{CH}_{3}\right)$ resonance (0.9 p.p.m.) does not show any appreciable change with the increase in the apoptotic cell fraction. Thus, the intensity of the methyl resonance can serve as an internal concentration reference when using the 1.3/0.9 p.p.m. resonance intensity ratio to monitor and assess treatment responses. Figure 4 shows the change of this ratio as a function of time for both control 


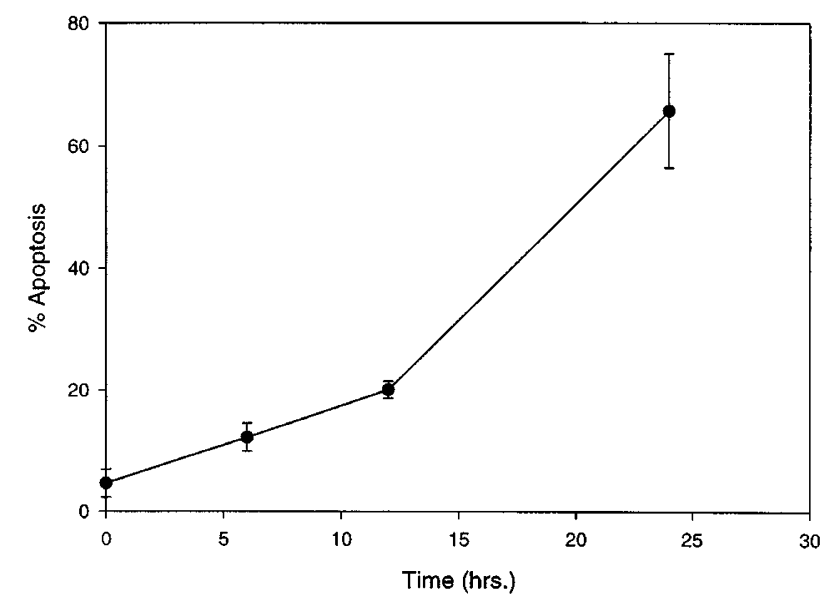

Figure 2 Plot of the percentage of apoptosis in HeLa cells as a function of time following treatment with etoposide. The results are the average of three independent experiments. Error bars indicate standard deviations

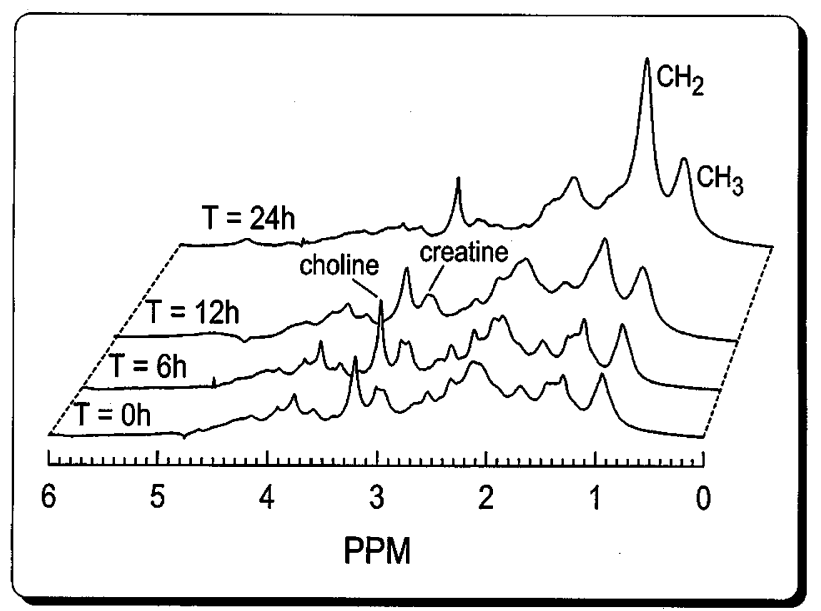

Figure $3{ }^{1} \mathrm{H}$ NMR spectra $(360 \mathrm{MHz})$ of $\mathrm{HeLa}$ cells suspended in $\mathrm{PBS} / \mathrm{D}_{2} \mathrm{O}$ before treatment and at several time points following treatment with etoposide

and etoposide-treated cells. As can be clearly seen in the figure, whereas the ratio remains almost constant for the control cells (over a period of $24 \mathrm{~h}$ ), that for the drugtreated cells has increased by a factor of three. This shows that the observed spectral changes are the result of the drug treatment and not reflections of some normal metabolic processes that may take place in the cells.

Figure 5 shows spectra of (A), control cells; (B), cells that were treated with ethacrynic acid for 90 min undergoing necrotic cell death; $(\mathrm{C})$, cells that were treated with etoposide for $24 \mathrm{~h}$ undergoing significant apoptosis and (D), cells that were first treated with etoposide for $24 \mathrm{~h}$ and then subjected to the treatment by ethacrynic acid for $90 \mathrm{~min}$. See figure legend for the actual percentages of necrotic and apoptotic cells. As can be seen in the figure, no significant change is observed in the intensity of the $\mathrm{CH}_{2}$ resonance during necrosis. The shaded resonances in the region between 3.4 to 3.9 p.p.m. (consistent with myoinositol and ethanolamine) and the resonances between 2.1

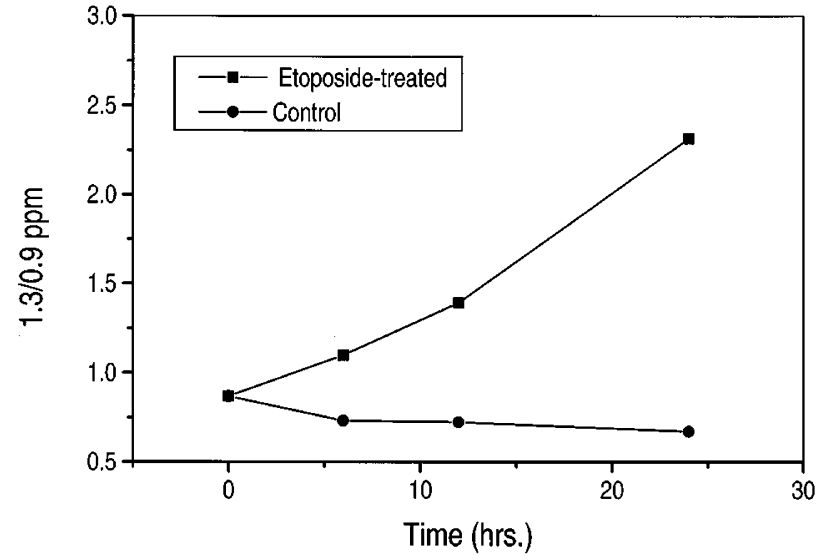

Figure 4 Plot of the 1.3/0.9 p.p.m. NMR spectral ratio as a function of time for both control and etoposide-treated HeLa cells

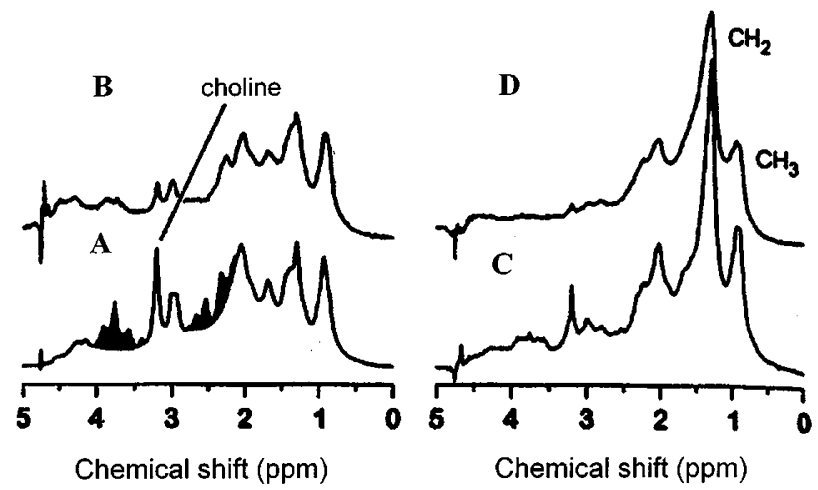

Figure $5{ }^{1} \mathrm{H}$ NMR spectra $(360 \mathrm{MHz})$ of HeLa cells (A) control $(6 \%$ apoptotic, $1 \%$ necrotic), (B) cells that were treated with ethacrynic acid for $90 \mathrm{~min}(96 \%$ necrotic cells), (C) cells that were treated with etoposide for $24 \mathrm{~h}$ (67\% apoptotic, $7 \%$ necrotic) and (D) cells that were first treated with etoposide for $24 \mathrm{~h}$ and then subjected to the treatment by ethacrynic acid for $90 \mathrm{~min}(62 \%$ apoptotic, $36 \%$ necrotic). See text for the explanation of the shaded region in (A)

and 2.9 p.p.m. (consistent with glutamine and glutamic acid) either completely disappear or are reduced drastically in their intensity (compare Figure 5A vs B). The change (decrease) in the choline intensity during necrotic cell death is also more marked than that seen during apoptosis (compare Figure 5B vs C). Figure 5D shows the cumulative effect of both apoptosis and necrosis with a further decrease in the intensity of the choline metabolite.

In addition to the use of ethacrynic acid, we have also used Cyt $B$ to induce necrosis. Although the mechanism by which it induces necrosis differs from that of ethacrynic acid, the spectral changes occurring were found to be similar (spectra not shown). Thus, the spectral changes that we see during the necrotic cell death are not drug-specific.

Figure 6 shows a linear regression fit of the percentage of apoptosis vs the spectral intensity ratio of the $\mathrm{CH}_{2} / \mathrm{CH}_{3}$ (1.3/0.9 p.p.m.) resonances. It shows a very good linear fit with an excellent correlation coefficient $\left(r^{2}=0.965\right.$, $P<0.003)$. This observation is significant since it corre- 


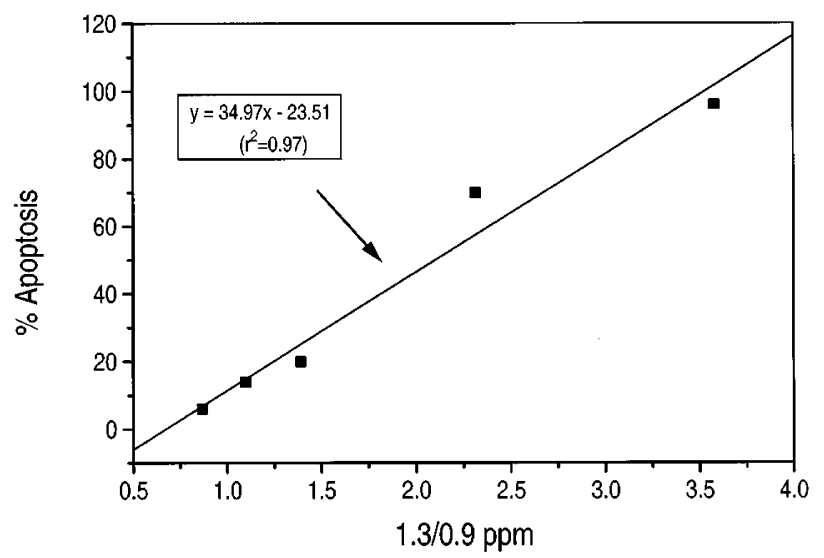

Figure 6 Plot of the linear regression of the percentage of apoptosis $v s$ the $1.3 / 0.9$ p.p.m. NMR spectral ratio in etoposide-treated HeLa cells $\left(r^{2}=0.965\right.$ $P<0.003)$

lates the complex process of apoptotic cell death with a readily measurable spectral quantity. One can thus gain an estimate of the extent of apoptosis from such a spectral ratio.

\section{Discussion}

Although the major contributor to the 1.3 p.p.m. resonance in Figure 3 is the methylene group $\left(-\mathrm{CH}_{2}-\right)$, contributions from the methyl group of lactate cannot be completely ruled out since we did not do any lactate editing. It is, however, unlikely that any substantial increases in the amounts of lactate could have taken place during the apoptotic process. In fact, Nunn et al. ${ }^{25}$ have shown a significant decrease in lactate levels in human neutrophils undergoing apoptosis. This was attributed to a decrease in lactate output and/or an increase in lactate metabolism. Thus, the contribution of the lactate signal, if present, would be to attenuate the increase in the intensity of the 1.3 p.p.m. resonance.

The increase in the intensity of the methylene resonance has been suggested to be due to the decreases in the plasma membrane microviscosity associated with the apoptotic process. ${ }^{23,26}$ These changes may also reflect the collapse of the transmembrane lipid asymmetry which results in surface exposure of phosphatidylserine, an early event in apoptosis. ${ }^{10}$ An increase in ceramide, a sphingolipid that is a major membrane component, has also been observed in a recent study during etoposideinduced apoptosis of Molt-4 human leukemia cells. ${ }^{27}$ This study provided evidence that ceramide, generated de novo, functions as a regulatory molecule in mediating membrane related apoptotic events. The increase in ceramide, with its long $-\mathrm{CH}_{2}$ - chain, could also explain the increase in the 1.3 p.p.m. signal intensity in our NMR spectra. The decrease in the signal intensity of the choline containing metabolites observed in our study is consistent with the possible induction of growth arrest that takes place during the onset of apoptosis.

These results have been found to be similar to those obtained with other cell lines including the Jurkat T-cell lymphoblasts when apoptosis was induced using doxorubicin treatment. ${ }^{24}$ Although the lack of an increase in the intensity of the 0.9 r.p.m. resonance observed in our study is in agreement with that of Blankenberg et al. ${ }^{23}$ it is at odds with that of Hakumaki et al., ${ }^{28}$ where a significant increase of this resonance was observed 4 days after treatment during gene therapy of glioma. However, since the mechanisms of cell death by gene therapy and chemotherapy are somewhat different, this difference in response is not surprising.

In the study of Hakumaki et al., ${ }^{28}$ BT4C gliomas transfected with the viral HSV-tk (herpes simplex thymidine kinase) gene were induced intracranially in female BDIX rats. The rats were then treated with intraperitoneal injections of ganciclovir (GCV) for 10 days. The killing resulted from the increased specificity of the HSV-tk for the drug GCV when compared to cellular thymidine kinases. The mechanism of action of the cytotoxic GCV is that it inhibits DNA polymerase causing termination of DNA synthesis, thus killing dividing cells. The study showed that the GCV-induced apoptosis of experimental gliomas is associated with a substantial accumulation of polyunsaturated fatty acids. Flow-cytometric studies have shown that GCV-induced apoptotic cell death is preceded by an irreversible arrest in the late S- or G2-phase and the amount of MRS-visible lipid has been shown to correlate with the proportion of cells in these stages. ${ }^{29,30}$ In contrast to this, etoposide kills cells predominantly by inhibiting topoisomerase II, whereas doxorubicin kills cells by DNA intercalation. Despite the differences in the drugs used and their mechanisms of action, and the different types of cells studied, the increase in the lipid signal, as evidenced by the increase in the 1.3 p.p.m. intensity, seems to hold in all situations. This provides credence and robustness to the use of this novel technique in the detection and quantification of apoptosis in drug-treated cancer cells. An extension of this work to other types of chemotherapeutic drugs that work through other mechanisms (e.g., alkylating agents, nitrosoureas, antimetabolites and mitotic inhibitors) should be undertaken in the future. This will help our understanding of the NMR spectral changes vis-à-vis factors such as cell-cycle dependence of the drugs, and resistance to treatment.

We did not perform any NMR relaxation measurements in this study. However, such experiments done in vivo ${ }^{28}$ and in vitro ${ }^{23}$ show no significant relaxation changes for the resonances of interest during apoptosis. Moreover, since the area under the resonances, and not just the peak heights were used to determine the signal intensities, changes in line width (as a result of $\mathrm{T}_{2}$ changes) would be accounted for in the analysis.

The similarity of these results to those that were previously reported $^{24}$ suggests that such an approach is applicable to various tumor types and with different drug treatments. In contrast to the results obtained with the doxorubicin-treated Jurkat T-cells, however, we see an earlier significant response (at $6 \mathrm{~h}$ ) in these etoposidetreated HeLa cells (see Figures 2 and 4). This could be related to the specific characteristics of the cells or the drug used. Although the emphasis of this study, and that of the 
previous work, has been on the changes in the lipid profiles in the spectra, there are also notable changes in other spectral regions (see Figure 5). To understand how these spectral changes are associated with the processes of apoptosis and necrosis requires further investigation.

Studies of this type should be performed with tumors in vivo in order to determine the utility of NMR spectroscopy to monitor treatment efficacy. Tumor heterogeneity and the short half-lives of apoptotic cells present challenges to overcome in this application. The ensuing macroscopic changes, however, can be detected by NMR at a reasonably early time after the induction of apoptosis. The recent in vivo results of Hakumaki et al. ${ }^{28}$ are very encouraging in this regard. Another challenge for in vivo NMR spectroscopy relates to the voxel size from which the measurement is taken from. Since the size of these voxels is currently much larger than the microscopic changes occurring in the tumor, discriminating between drug-induced apoptosis and spontaneously occurring necrosis poses a serious challenge. However, with the advances being made in NMR microscopy, we may soon be able to study tumors with the resolution required for such a microscopic discrimination.

\section{Conclusions}

NMR spectroscopy allows the early detection (after $6 \mathrm{~h}$ ) of apoptosis-induced cellular changes in human cervical carcinoma cells by observing signals from small and mobile molecular species, particularly the ratio of intensities of the $\mathrm{CH}_{2}$ and $\mathrm{CH}_{3}$ resonances. Because NMR spectroscopy is non-invasive and can be readily used in vivo, its application to anticancer drug testing should provide a tool for detecting the early onset of apoptosis and assessing the therapeutic response of in situ tumor cells subjected to chemotherapeutic cytotoxic drugs.

\section{Materials and Methods}

HeLa cells were grown at $37^{\circ} \mathrm{C}$ in an incubator with $5 \% \mathrm{CO} 2$ in $\alpha$ MEM with L-glutamine (GIBCO, BRL Life Technologies Inc.), supplemented with $0.2 \% \mathrm{NaHCO}_{3}$, penicillin $(100 \mathrm{U} / \mathrm{ml})$, streptomycin $(100 \mu \mathrm{g} / \mathrm{ml})$ and $10 \%$ fetal bovine serum. Apoptosis was induced by treatment with $10 \mu \mathrm{M}$ etoposide in DMSO for 6,12 , and $24 \mathrm{~h}$. The percentage of apoptotic cells was determined by nuclear morphology counting $\sim 400$ cells/sample stained with Hoechst dye. Also, staining with acridine orange and ethidium bromide combined with fluorescent microscopy was used to distinguish early apoptotic cells from necrotic cells. ${ }^{31}$ Acridine orange intercalates into the DNA, giving it a green appearance and thus, viable cells appear with a green nucleus and early apoptotic cells with a condensed or fragmented nuclei. Ethidium bromide is taken up only by non-viable cells giving a bright orange nucleus of dead cells overwhelming the acridine orange stain. Necrosis was induced by treatment with ethacrynic acid $(1.5 \mu \mathrm{g} / \mathrm{ml})$ for $1.5 \mathrm{~h}$. In addition, apoptotic cells $(24 \mathrm{~h})$ were also treated with ethacrynic acid for $1.5 \mathrm{~h}$. Cytochalasin $\mathrm{B}$ was used at a concentration of $10 \mu \mathrm{M}$ for $24 \mathrm{~h}$.

Control cells and those harvested at 6, 12 and $24 \mathrm{~h}$ after treatment were washed with PBS twice, before being subjected to ${ }^{1} \mathrm{H}$ NMR spectroscopy. ${ }^{1} \mathrm{H}$ NMR spectra were recorded on cells $\left(1 \times 10^{8}\right)$ suspended in $600 \mu \mathrm{PBS} / \mathrm{D}_{2} \mathrm{O}$ in a 5-mm NMR tube. One-dimensional spectra were acquired on a Bruker AM-360 spectrometer at $25^{\circ} \mathrm{C}$ with the sample spinning at $20 \mathrm{~Hz}$. The residual $\mathrm{H}_{2} \mathrm{O}$ signal at $~ 4.6$ p.p.m. was suppressed by presaturation. The acquisition parameters included: $90^{\circ}$ pulse, 256 scans, spectral width of $5 \mathrm{KHz}$, recycle delay of $2 \mathrm{~s}$, and time domain of $4 \mathrm{~K}$ data points. Signal intensities were calculated by performing appropriate baseline correction and then integrating the area under each of the resonances using standard Bruker integration software.

\section{Acknowledgements}

We would like to thank Dr. Chris Schultz for his helpful discussions. This research was funded by grants from the CancerCare Manitoba to $M$ Mowat and the Natural Sciences and Engineering Research Council of Canada to ICP Smith. This work was presented in part at the meeting of the International Society of Magnetic Resonance in Medicine, Sydney, Australia, 1998.

\section{References}

1. Majno G and Joris I (1995) Apoptosis, oncosis, and necrosis: An overview of cell death. Am. J. Pathol. 146: 3-15

2. Wyllie AH, Kerr JFR and Currie AR (1980) Cell death: the significance of apoptosis. Int. Rev. Cytol. 68: 251-306

3. Kerr JFR, Winterford CM and Harmon BV (1994) Apoptosis: its significance in cancer and cancer therapy. Cancer 73: 2013-2026

4. Dive C, Gregory CD, Phipps DJ, Evans DL, Milner AE and Wyllie AH (1992) Analysis and discrimination of necrosis and apoptosis (programmed cell death) by multiparameter flow cytometry. Biochim. Biophys. Acta 1133: 275-285

5. Nicholson DW and Thornberry NA (1997) Caspases: killer proteases. Trends Biochem. Sci. 22: 299-306

6. Walker PR and Sikorska M (1994) Endonuclease activities, chromatin structure, and DNA degradation in apoptosis. Biochem. Cell Biol. 72: 615-623

7. Liu XS, Zou H, Slaughter C and Wang XD (1997) DFF, a heterodimeric protein that functions downstream of caspase-3 to trigger DNA fragmentation during apoptosis. Cell 89: 175-184

8. Sakahira H, Enari M and Nagata S (1998) Cleavage of CAD inhibitor in CAD activation and DNA degradation during apoptosis. Nature 391: 96-99

9. Enari M, Sakahira H, Yokoyama H, Okawa K, Iwamatsu A and Nagata S (1998) A caspase-activated DNase that degrades DNA during apoptosis, and its inhibitor ICAD. Nature 391: 43-50

10. Fadok VA, Bratton DL, Frasch SC, Warner ML and Henson PM (1998) The role of phosphatidylserine in recognition of apoptotic cells by phagocytes. Cell Death Differ. 5: $551-562$

11. Savill J, Hogg N, Ren Y and Haslett C (1992) Thrombospondin cooperates with CD36 and the vitronectin receptor in macrophage recognition of neutrophils undergoing apoptosis. J. Clin. Invest. 90: 1513-1522

12. Dragovich T, Rudin CM and Thompson CB (1998) Signal transduction pathways that regulate cell survival and cell death. Oncogene 17: 3207-3213

13. Nicotera $P$ and Leist $M$ (1997) Energy supply and the shape of death in neurons and lymphoid cells. Cell Death Differ. 4: 435-442

14. Moore JV (1987) Death of cells and necrosis of tumors. In Perspectives on Mammalian Cell Death. CS Potten, (ed). Oxford University Press: Oxford, pp. $295-324$

15. Naik P, Karrim J and Hanahan D (1996) The rise and fall of apoptosis during multistage tumorigenesis: Down-modulation contributes to tumor progression from angiogenic progenitors. Genes Dev. 10: 2105-2116

16. Cory S, VauxDL, Strasser A, Harris AW and Adams JM (1999) Insights from Bcl-2 and Myc: Malignancy involves abrogation of apoptosis as well as sustained proliferation. Cancer Res. 59: 1685S-1692S

17. Hande KR (1998) Etoposide: four decades of development of a topoisomerase II inhibitor. Eur. J. Cancer 10: 1514-1521 
18. Russo MA and Rossum GD (1986) The basis for the cellular damage induced by ethacrynic acid in liver slices in vitro. Comparison of structure and function. Lab. Invest. 54: 695-707

19. Lin S and Spudich JA (1974) On the molecular basis of action of cytochalasin B. J Supramol. Struct. 2: $728-736$

20. Cotter TG, Lennon SV, Glynn JM and Green DR (1992) Microfilament-disrupting agents prevent the formation of apoptotic bodies in tumor cells undergoing apoptosis. Cancer Res. 52: 997-1005

21. Engelmann J, Henkel J, Willker W, Kutscher B, Nossner G, Engel J and Leibfritz D (1996) Early stage monitoring of miltefosine induced apoptosis in KB cells by multinuclear NMR spectroscopy. Anticancer Res. 16: 1429-1440

22. Bogin L, Papa MZ, Polak-Charcon S and Degani H (1998) TNF-induced modulations of phospholipid metabolism in human breast cancer cells. Biochim. Biophys. Acta 1392: 217-232

23. Blankenberg FG, Storrs RW, Naumovski L, Goralski T and Spielman D (1996) Detection of apoptotic cell death by proton nuclear magnetic resonance spectroscopy. Blood 87: 1951-1956

24. Blankenberg FG, Katsikis PD, Storrs RW, Beaulieu C, Spielman D, Chen JY Naumovski L and Tait JF (1997) Quantitative analysis of apoptotic cell death using proton nuclear magnetic resonance spectroscopy. Blood 89: 3778-3786

25. Nunn AVW, Barnard ML, Bhakoo K, Murray J, Chilvers EJ and Bell JD (1996) Characterization of secondary metabolites associated with neutrophi apoptosis. FEBS Lett. 392: 295-298
26. Delikatny EJ, Lander CM, Jeitner TM, Hancock R and Mountford CE (1996) Modulation of MR-visible lipid levels by cell culture conditions and correlations with chemotactic response. Int. J. Cancer 65: 238-245

27. Perry DK, Carton J, Shah AK, Meredith F, Uhlinger DJ and Hannun YA (2000) Serine palmitoyltransferase regulates de novo ceramide generation during etoposide-induced apoptosis. J. Biol. Chem. 275: 9078-9084

28. Hakumaki JM, Poptani H, Sandmair AM, Yla-Herttuala S and Kauppinen RA (1999) ${ }^{1} \mathrm{H}$ MRS detects polyunsaturated fatty acid accumulation during gene therapy of glioma: Implications for the in vivo detection of apoptosis. Nature Med. 5: $1323-1327$

29. Wei SJ, Chao Y, Hung YM, Lin WC, Yang DM, Shih YL, Ch'ang LY, WhangPeng J and Yang WK (1998) S- and G2-phase cell cycle arrests and apoptosis induced by ganciclovir in murine melanoma cells transduced with herpes simplex virus thymidine kinase. Exp. Cell Res. 241: 66-75

30. Veale MF, Roberts NJ, King GF and King NJ (1997) The generation of $1 \mathrm{H}$ NMR detectable mobile lipid in stimulated lymphocytes: Relationship to cellular activation, the cell cycle, and phosphatidylcholine-specific phospholipase C. Biochem. Biophys. Res. Commun. 239: 868-874

31. McGahon AJ, Martin SJ, Bissonnette RP, Mahboubi A, Shi Y, Mogil RJ, Nishioka WK and Green DR (1995) The end of the (cell) line: methods for the study of apoptosis in vitro. Methods Cell Biol. 46: 153-185 